ANL-6365

Reactor Technology (TID-4500, 16th Ed.)

AEC Research and

Development Report

ARGONNE NATIONAL LABORATORY

9700 South Cass Avenue

Argonne, Illinois

FLUX AND TEMPERATURE PEAKING EFFECTS

RESULTING FROM THE USE OF SEAMED

FUEL TUBES IN CP-5

by

D. P. Moon

Reactor Engineering Division

May 1961

Operated by The University of Chicago under

Contract W-31-109-eng-38 


\section{DISCLAIMER}

This report was prepared as an account of work sponsored by an agency of the United States Government. Neither the United States Government nor any agency Thereof, nor any of their employees, makes any warranty, express or implied, or assumes any legal liability or responsibility for the accuracy, completeness, or usefulness of any information, apparatus, product, or process disclosed, or represents that its use would not infringe privately owned rights. Reference herein to any specific commercial product, process, or service by trade name, trademark, manufacturer, or otherwise does not necessarily constitute or imply its endorsement, recommendation, or favoring by the United States Government or any agency thereof. The views and opinions of authors expressed herein do not necessarily state or reflect those of the United States Government or any agency thereof. 


\section{DISCLAIMER}

Portions of this document may be illegible in electronic image products. Images are produced from the best available original document. 
TABLE OF CONTENTS

Page

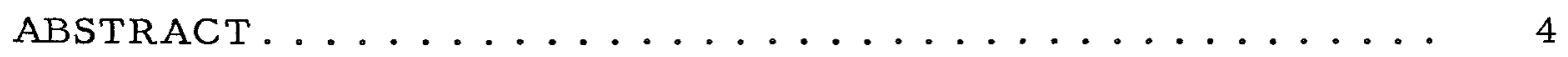

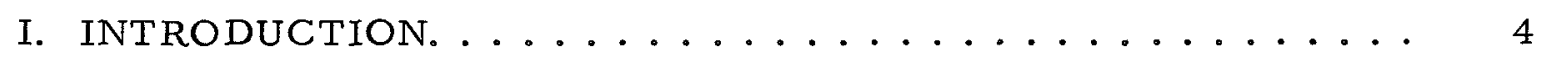

II. FUEL ELEMENT SPECIFICATIONS ............... 5

III. EXPERIMENTAL DATA ........................ 7

IV. THEORETICAL FLUX PEAKING FACTORS .......... 10

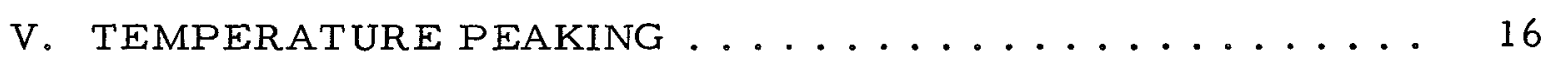

VI. CONCLUSIONS....................... 18

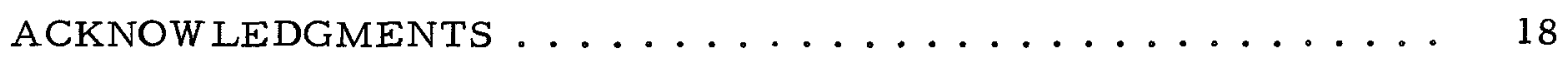




\section{LIST OF FIGURES}

No.

Title

Page

1. Horizontal Cross Section of CP-5 Core Showing Fuel

Element Locations ...................... 5

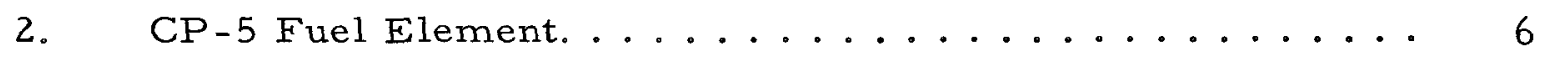

3. CP-5 Fuel Thimble Seam................. 8

4. Ratio of Local Gamma Intensity to Average Gamma

Intensity as a Function of Angular Position Near the Lower

End of the Fuel Thimble .................... 9

5. Ratio of Local Gamma Intensity to Average Gamma

Intensity as a Function of Angular Position Near the

Vertical Center of the Fuel Thimble ............

6. Radial Thermal and Fast Fluxes as Calculated by

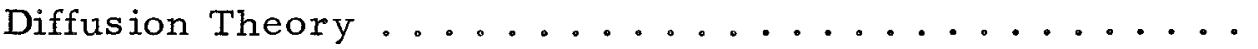

7. Ratio of Local Thermal Flux Within Meat to Thermal Flux

Opposite Seam as a Function of Angular Position from

Center of Fuel Thimble Seam $(1.27 \mathrm{~cm}$ wide $) .. . . . .$.

8. Ratio of Local Thermal Flux Within Meat to Thermal Flux

Opposite Seams as a Function of Angular Position for Fue1

Element Containing Tubes with Seams $(0.95 \mathrm{~cm}$ wide) in

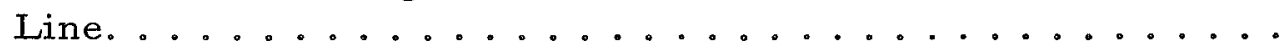

9. Theoretical Ratio of Local Power Density to Average Power Density as a Function of Annular Position Near the Lower

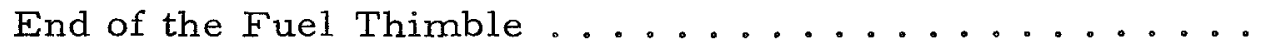

10. Theoretical Ratio of Local Power Density to Average Power Density as a Function of Angular Position Near the Vertical Center of the Fuel Thimble ............

\section{LIST OF TABLES}

No.

Title

Page

I. Radial Dimensions of CP-5 Fuel Tubes ........... 6

II. Nuclear Constants .................... 11

III. Adjusted Theoretical Peaking Factors ............ 15 


\title{
FLUX AND TEMPERATURE PEAKING EFFECTS RESULTING FROM THE USE OF SEAMED FUEL TUBES IN CP-5
}

by

D. P. Moon

\begin{abstract}
The flux peaking factor resulting from the use of a seamed fuel thimble in CP-5 has been determined experimentally and by diffusion theory calculations. A comparison of the two methods indicates that an underestimation of the magnitude and sharpness of the flux peak is obtained from the diffusion calculations. Based on this comparison, a conservative calculation of the peaking effect which would result from the use of seamed fuel tubes in CP- 5 indicates a maximum local power-peaking factor of 1.10 and a maximum fuel surface temperature $3^{\circ} \mathrm{C}$ above that obtained with extruded tubes for the same total reactor power and the same flow conditions.
\end{abstract}

\section{INTRODUCTION}

The Research Reactor CP-5, located at Argonne National Laboratory, uses a fuel element consisting of a bundle of three concentric, extruded fuel tubes, each consisting of $\mathrm{Al}-\mathrm{U}^{235}$ alloy clad with aluminum. The main advantage of such fuel elements is the relatively large number of irradiation facilities available within the innermost tubes. A significant disadvantage has been the high cost of fuel elements due to the difficulty of fuel-tube fabrication by the extrusion process.

Fabrication of CP-5 fuel tubes by rolling and welding of flat plates is under consideration. This method provides a fuel tube at lower cost than does the extrusion process. It also introduces a longitudinal aluminum seam, extending the length of the fuel tube, which causes a local flux and power peaking. The magnitude of this peaking effect and the resultant increase of the surface temperature of the fuel tube is of importance in evaluating the value of the new fabrication procedure. 


\section{FUEL ELEMENT SPECIFICATIONS}

A maximum of seventeen tubular fuel elements, spaced as shown in Fig. I, forms the core of CP-5. The fuel elements are constructed as shown in Fig. 2. The radial dimensions for the individual fuel elements are listed in Table I. This table also includes the dimensions of the fuel thimbles which are inserted within certain of the fuel elements, after long operation, in order to increase the available reactivity. These fuel thimbles are fabricated by a rolling and welding operation which introduces a $1.27-\mathrm{cm}-$ wide longitudinal seam running the length of the thimble.

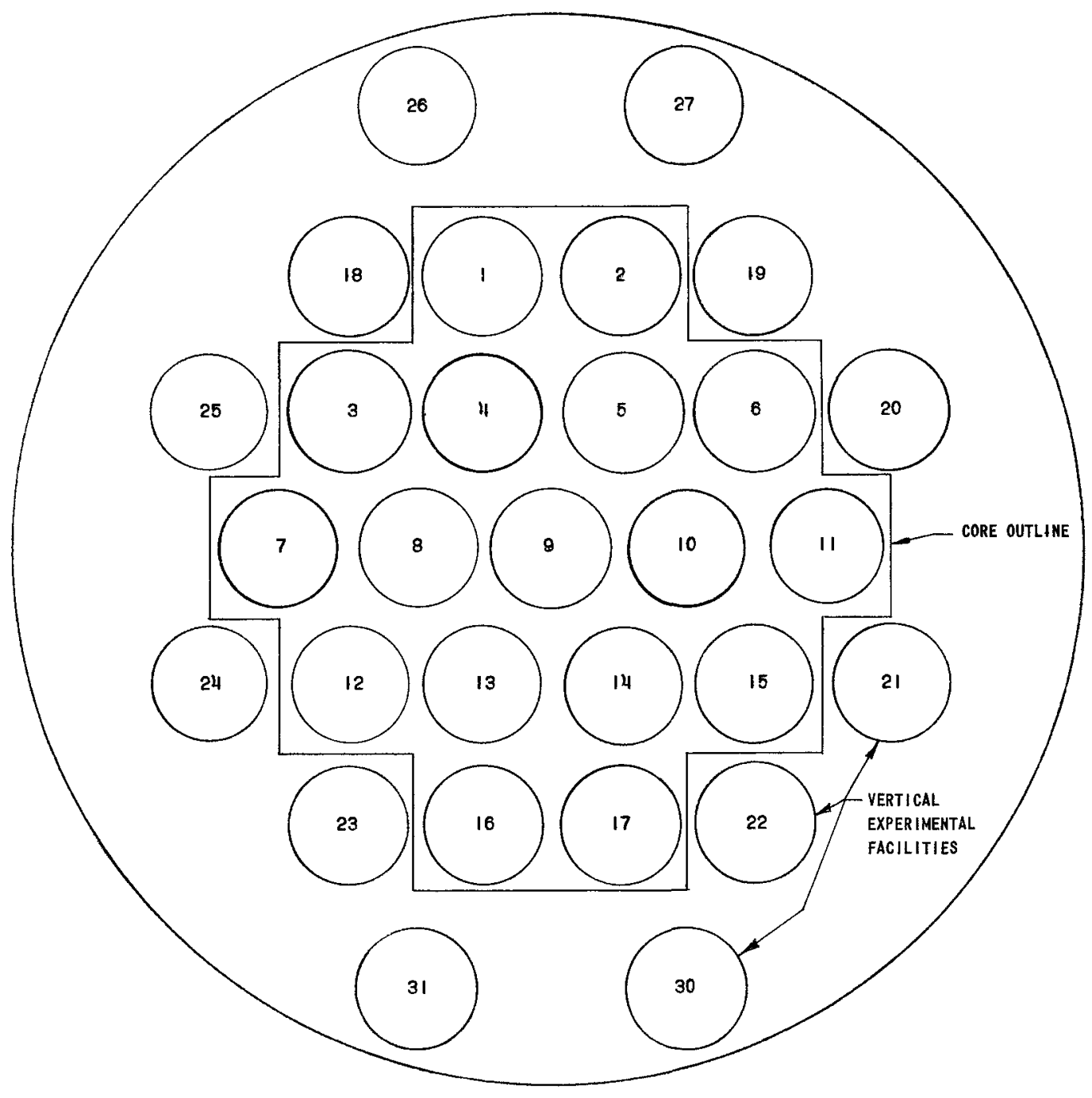

FIG. I

HORIZONTAL CROSS SECTION OF CP-5 CORE SHOWING FUEL ELEMENT LOCATIONS 


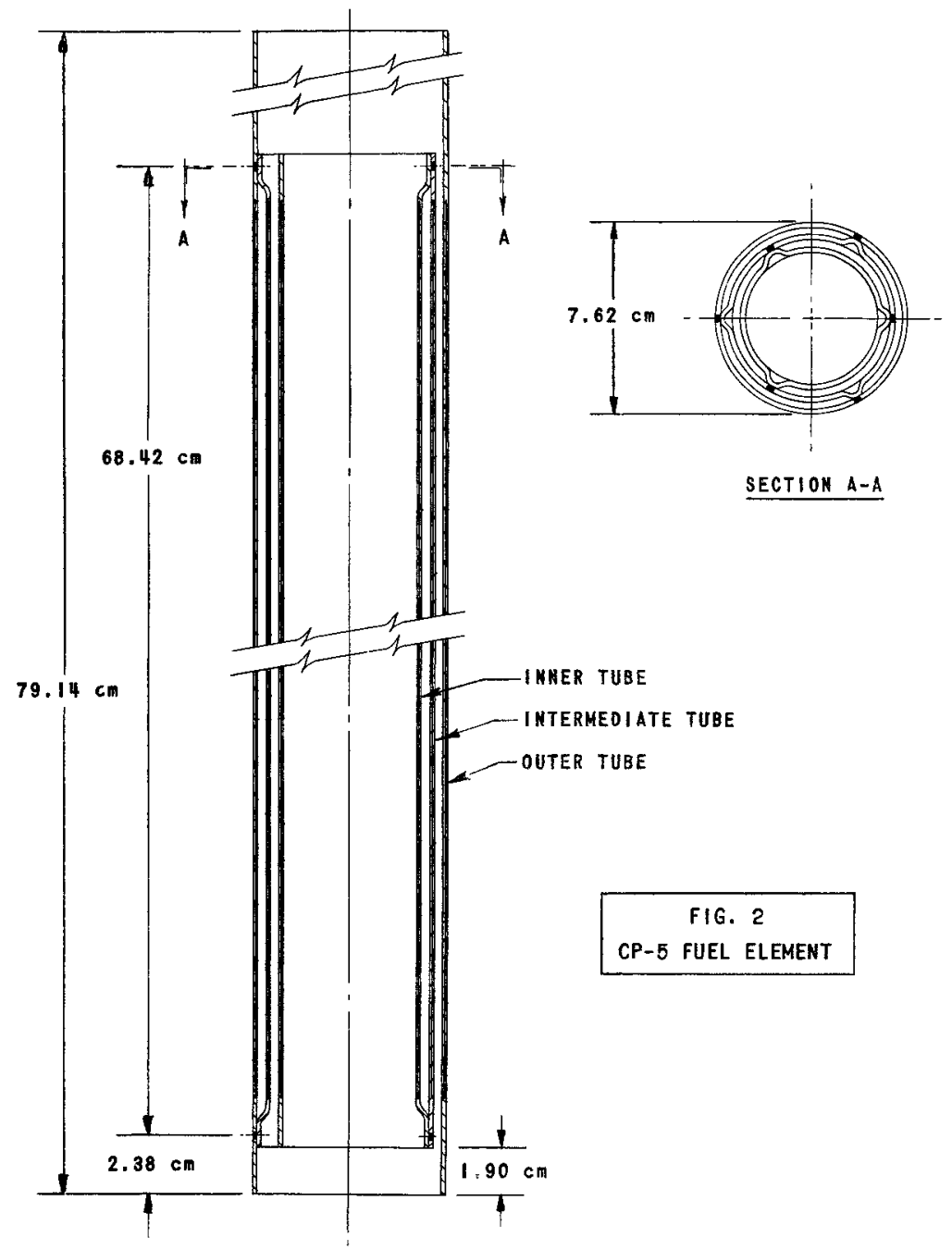

Table I

\section{RADIAL DIMENSIONS OF CP - 5 FUEL TUBES}

\begin{tabular}{|c|c|c|c|c|}
\hline & $\begin{array}{c}\text { Fuel } \\
\text { Thimble }\end{array}$ & $\begin{array}{l}\text { Inner } \\
\text { Tube }\end{array}$ & $\begin{array}{c}\text { Intermediate } \\
\text { Tube }\end{array}$ & $\begin{array}{l}\text { Outer } \\
\text { Tube }\end{array}$ \\
\hline Tube Inner Radius $(\mathrm{cm})$ & 2.115 & 2.682 & 3.195 & 3.683 \\
\hline Core Inner Radius (cm) & 2.168 & 2.720 & 3.233 & 3.721 \\
\hline Core Outer Radius (cm) & 2.249 & 2.802 & 3.315 & 3.772 \\
\hline Tube Outer Radius $(\mathrm{cm})$ & 2.302 & 2.840 & 3.353 & 3.810 \\
\hline Core Thickness $(\mathrm{cm})$ & 0.081 & 0.081 & 0.081 & 0.051 \\
\hline Cladding Thickness $(\mathrm{cm})$ & 0.053 & 0.038 & 0.038 & 0.038 \\
\hline Tube Wall Thickness $(\mathrm{cm})$ & 0.187 & 0.157 & 0.157 & 0.127 \\
\hline
\end{tabular}


The fuel tubes contain a core of aluminum-uranium alloy formed from uranium that is $93 \%$ enriched in $U^{235}$. The core section within any one tube has an extreme alloy variation of no more than $\pm \frac{1}{2} w t-\% U^{235}$. The mass of $\mathrm{U}^{235}$ in the core sections of the inner fuel tubes is $62.1 \pm 3 \mathrm{gm}$, in the intermediate fuel tubes $73.5 \pm 3 \mathrm{gm}$, and in the outer fuel tubes $34.6 \pm 3 \mathrm{gm}$. Fuel tubes are delivered in matched sets such that the total mass of $U^{235}$ in each fuel element is $170.1 \pm 4 \mathrm{gm}$.

The mass of $\mathrm{U}^{235}$ per fuel thimble varies from $36.7 \mathrm{gm}$ to $40.6 \mathrm{gm}$. Before being formed into fuel thimble tubes, rolled plates are sheared to leave $0.32 \mathrm{~cm}$ of clad at each edge of the core to permit the seam weld to be made. This results in a nominal $0.64-\mathrm{cm}$-wide unfueled seam along the length of the tube. The seam is actually $1.27 \mathrm{~cm}$ wide after welding (see Fig. 3).

\section{EXPERIMENTAL DATA}

The gamma intensity of a single fuel thimble has been observed as a function of angular position at several different horizontal planes. This fuel thimble had been located within a fuel element at location number five (see Fig. 1) for a period of two months during full-power operation. It had decayed for a period of approximately one year before any measurements were made.

A lead pinhole collimator $(0.1 \mathrm{~cm} \times 0.3 \mathrm{~cm} \times 20-\mathrm{cm}$-opening) plus a 3.8-cm-diameter lead plug located within the thimble were used to ensure an accurate measure of the gamma intensity with position. A NaI scintillator with associated electronic equipment was used to measure the gamma intensity. The assumption has been made that the gamma intensity less background at any position is proportional to the time integral of the power density within the fuel meat at that position.

In order to obtain the gamma intensity at a given angular position, the collimator and detector were kept fixed and the fuel thimble rotated within a lead shield. An angular location indicator was used, which was divided into 44 segments equally spaced around a circle of $110-\mathrm{cm}$ circumference. By means of this method, an accuracy of location which corresponded to a circumferential distance on the thimble of $0.2 \mathrm{~cm}$ could easily be obtained.

Figures 4 and 5 show the data obtained at two different vertical positions for a single fuel thimble. The ratio of the gamma intensity to the average gamma intensity, $I / \bar{I}$, is plotted versus angular position. The data were reproducible within experimental error. 

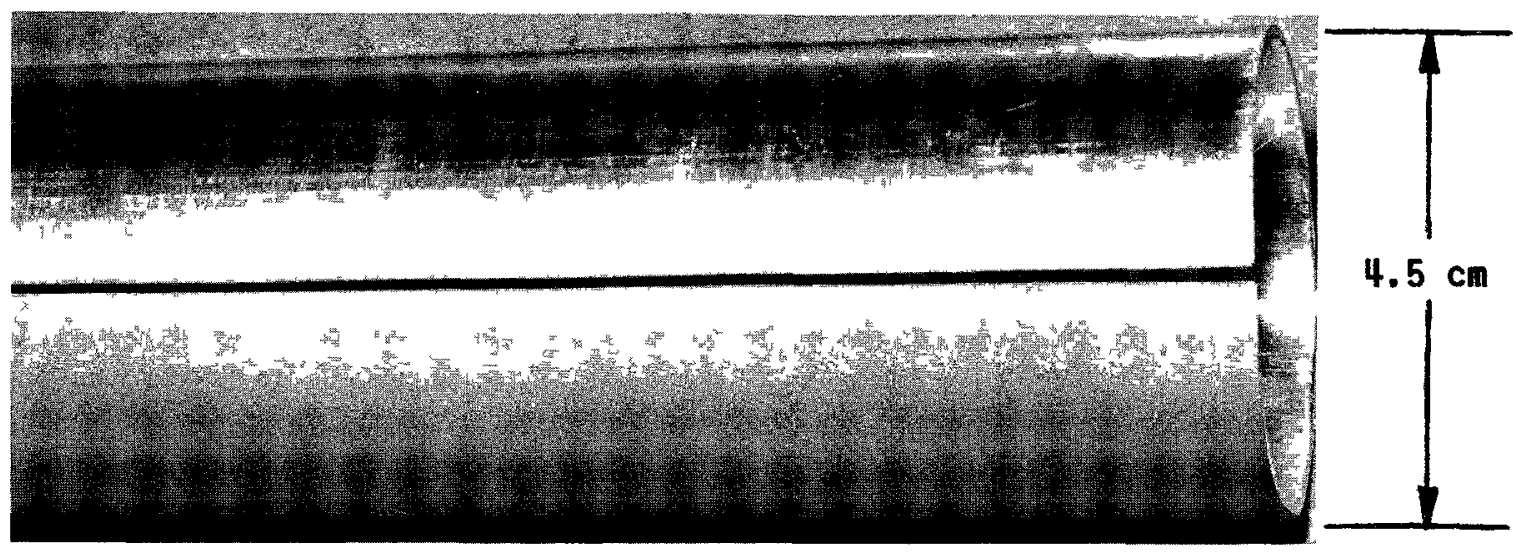

\section{UNWELDED TUBE}
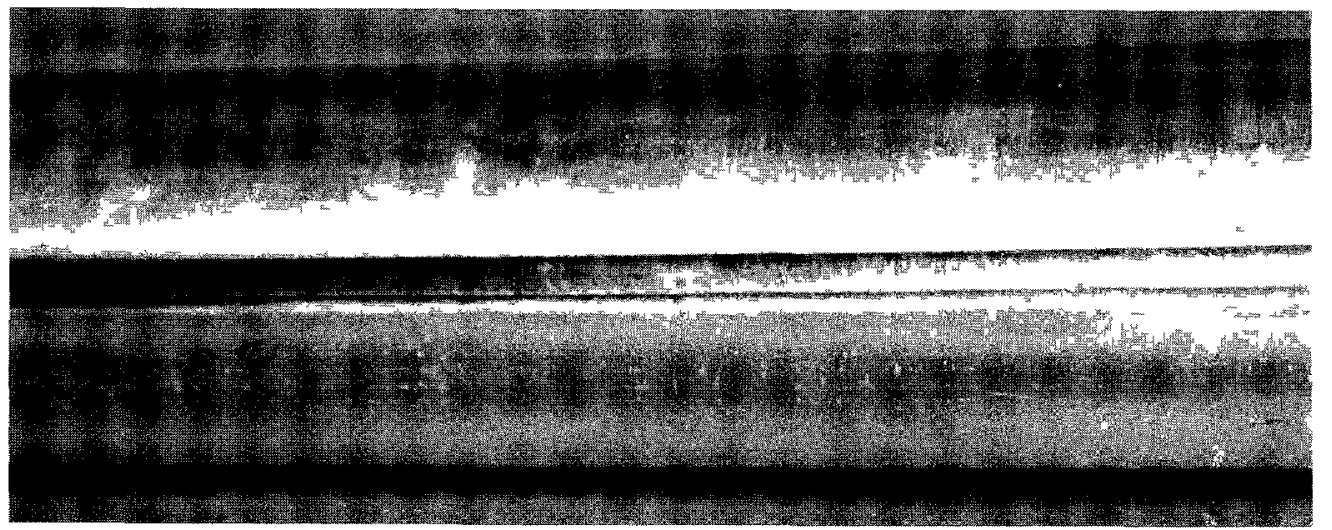

WELDED TUBE

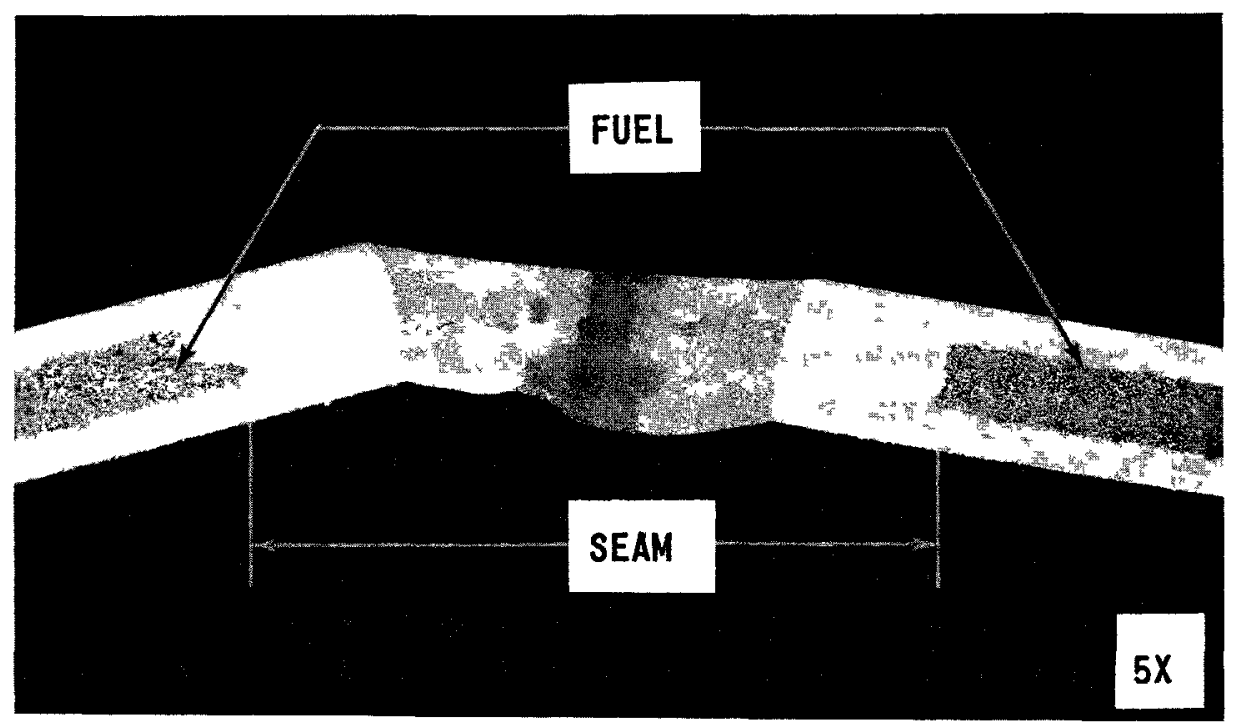

SEAM CROSS SECTION

FIG. 3

CP-5 FUEL THIMBLE SEAM 


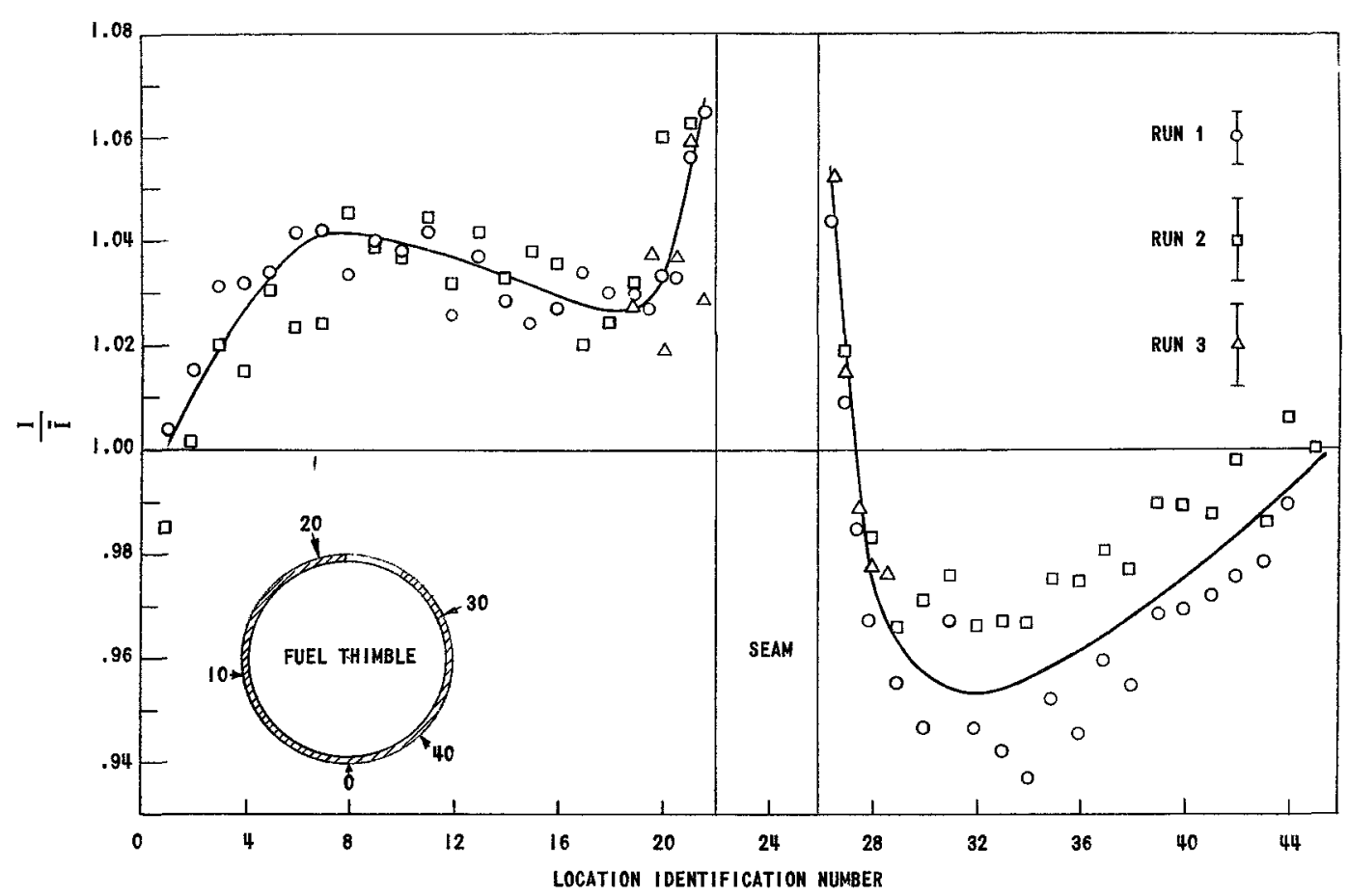

FIG. 4

RATIO OF LOCAL GAMMA INTENSITY TO AVERAGE GAMMA INTENSITY AS A FUNCTION OF ANGULAR POSITION NEAR THE LOWER END OF THE FUEL THIMBLE

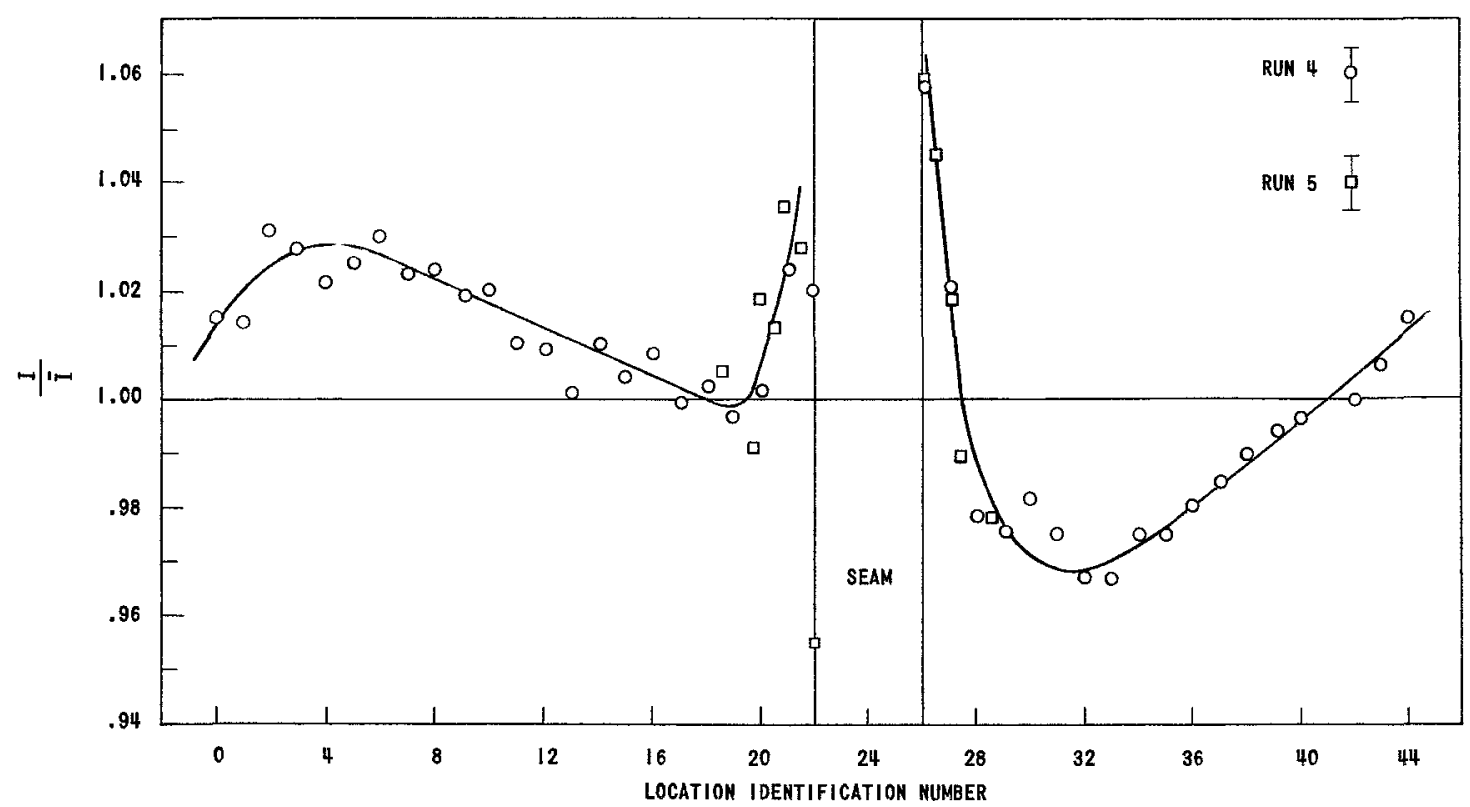

FIG. 5

RATIO OF LOCAL GAMMA INTENSITY TO AVERAGE GAMMA INTENSITY AS A FUNCTION OF ANGULAR POSITION NEAR THE VERTICAL CENTER OF THE FUEL THIMBLE 
An observable power peak occurs at the interface of the aluminum seam and the fuel meat. This peak is superimposed on a sinusoidal variation of the power density, which is the result of an approximately linear gradient of thermal flux across the tube. It can be noticed that the sinusoid is shifted slightly with respect to the seam at the two different vertical positions.

The experiments were done with a minimum of equipment and time; hence the inherent errors were not kept to a minimum. The ranges of possible error shown in Figs. 4 and 5 correspond to the root-mean-square of a sum of maximum errors (except for the statistical uncertainty in the gamma counting, in which case one standard deviation was used).

At the seam-meat interfaces, the variation of the gamma intensity between runs was in some cases larger than the error quoted. This most probably resulted from the nonuniformity of the fuel at this location (see Fig. 3). Fuel nonuniformity also caused the only slight peaking at locations $21-22$ shown in Fig. 5. Otherwise, one would expect the ratio $I / \bar{I}$ to be greater at these locations than at location 26.

Although the maximum peaking effect is delineated sufficiently well for the purpose of evaluating the seamed fuel tube concept, additional experimental observations of the peaking effects within the fuel tubes, as well as the thimbles, are planned in order to provide a more accurate and complete comparison for the theoretical calculations. In addition other peaking effects could be easily measured.

\section{THEORETICAL FLUX PEAKING FACTORS}

Local flux-peaking effects near the seams were calculated by the CURE ${ }^{a}$ diffusion code using two neutron energy groups and $R-\theta$ geometry. A total of 17 distinct radial regions were included to account for all $\mathrm{D}_{2} \mathrm{O}$ aluminum cladding, and $\mathrm{Al}-\mathrm{U}^{235}$ regions separately. The nuclear constants used for various assumed seam widths are listed in Table II.

Separate CURE problems were used to obtain flux and power distributions for the following configurations:

1. standard fuel element with no seams;

2. standard fuel element containing a seamed fuel thimble (seam widths of $0.64 \mathrm{~cm}, 0.95 \mathrm{~cm}$, or $1.27 \mathrm{~cm}$ );

aF.M. Trantham, Jr., CURE - A Two-space-dimension, Multi-group Code for the IBM-704, APEX 452 (Aug 1958). 
3. fuel element with each of the three tubes containing a seam of 0.64 (or 0.95) $-\mathrm{cm}$ width located at the same angular position for each tube; and

4. fuel element with each of the three tubes containing a seam of $0.95-\mathrm{cm}$ width located at an angular position $120^{\circ}$ out of phase with the seams of the other two tubes.

Table II

\section{NUCLEAR CONSTANTS}

\begin{tabular}{|c|c|c|c|c|c|c|}
\hline & $\begin{array}{l}\text { Fuel } \\
\text { Thimble } \\
\text { Meat }\end{array}$ & $\begin{array}{l}\text { Inner } \\
\text { Fuel Tube } \\
\text { Meat }\end{array}$ & $\begin{array}{l}\text { Intermediate } \\
\text { Fuel Tube } \\
\text { Meat }\end{array}$ & $\begin{array}{l}\text { Outer } \\
\text { Fuel Tube } \\
\text { Meat }\end{array}$ & $\mathrm{D}_{2} \mathrm{O}$ & $\mathrm{Al}$ \\
\hline $\mathrm{U}^{235}(\mathrm{gm})$ & 34.1 & 62.1 & 73.5 & 34.6 & - & - \\
\hline $\mathrm{D}_{1}(\mathrm{~cm})$ & 3.6 & 3.6 & 3.6 & 3.6 & 1.25 & 3.86 \\
\hline$\Sigma_{1}\left(\mathrm{~cm}^{-1}\right)$ & 0.00006 & 0.00006 & 0.00006 & 0.00006 & 0.010 & 0.00006 \\
\hline$\Sigma_{r_{1}}\left(\mathrm{~cm}^{-1}\right)$ & 0.002 & 0.003 & 0.003 & 0.002 & 0.010 & 0.00052 \\
\hline$\Sigma_{f_{1}}\left(\mathrm{~cm}^{-1}\right)$ & 0 & 0 & 0 & 0 & 0 & 0 \\
\hline \multicolumn{7}{|l|}{$\mathrm{D}_{2}(\mathrm{~cm})$} \\
\hline No seam & 0.393 & 0.282 & 0.298 & 0.411 & 0.80 & 3.37 \\
\hline $0.64-\mathrm{cm}$ seam & 0.379 & 0.273 & 0.275 & 0.402 & 0.80 & 3.37 \\
\hline $0.95-\mathrm{cm}$ seam & 0.370 & 0.268 & 0.271 & 0.397 & 0.80 & 3.37 \\
\hline $1.27-\mathrm{cm}$ seam & 0.363 & - & - & - & 0.80 & 3.37 \\
\hline \multicolumn{7}{|l|}{$\Sigma_{r_{2}}\left(\mathrm{~cm}^{-1}\right)$} \\
\hline No seam & 0.755 & 1.081 & 1.079 & 0.717 & $5.4 \times 10^{-5}$ & 0.012 \\
\hline $0.64-\mathrm{cm}$ seam & 0.787 & 1.121 & 1.113 & 0.737 & $5.4 \times 10^{-5}$ & 0.012 \\
\hline $0.95-\mathrm{cm}$ seam & 0.807 & 1.143 & 1.131 & 0.747 & $5.4 \times 10^{-5}$ & 0.012 \\
\hline $1.27-\mathrm{cm}$ seam & 0.825 & - & - & - & $5.4 \times 10^{-5}$ & 0.012 \\
\hline & 0 \\
\hline $0.64-\mathrm{cm}$ seam & 0.651 & 0.931 & 0.924 & 0.608 & 0 & 0 \\
\hline $0.95-\mathrm{cm}$ seam & 0.667 & 0.949 & 0.939 & 0.617 & 0 & 0 \\
\hline 1.27-cm seam & 0.682 & - & - & - & 0 & 0 \\
\hline \multicolumn{3}{|c|}{$D_{1}=$ fast diffusion coefficient } & \multicolumn{4}{|c|}{$D_{2}=$ thermal diffusion coefficient } \\
\hline \multicolumn{3}{|c|}{$\Sigma_{1}=$ slowing down cross section } & \multicolumn{4}{|c|}{$\Sigma_{r_{2}}=$ thermal absorption cross section } \\
\hline \multicolumn{3}{|c|}{$\begin{array}{l}\Sigma_{r_{1}}=\text { total fast removal cross section } \\
\Sigma_{f_{1}}=\text { fast group fission cross section }\end{array}$} & \multicolumn{4}{|c|}{$\Sigma_{f_{2}}=$ thermal fission cross section } \\
\hline
\end{tabular}

The radial thermal and fast fluxes obtained from problems (1) and (2) are shown in Fig. 6. The fuel thimble is represented by $F_{1}$, the inner fuel tube by $\mathrm{FT}_{2}$, the intermediate fuel tube by $\mathrm{FT}_{3}$, and the outer tube by $\mathrm{FT}_{4}$.

The flux peaking (as a function of angular position) at the radial center of each fuel tube is shown in Fig. 7 for the configuration consisting 
of a seamed (1.27-cm-wide seam) fuel thimble within an element of three extruded tubes. In Fig. 8 the flux peaking is shown for the case in which the three fuel tubes each contain $0.93-\mathrm{cm}$-wide seams positioned "in-line."

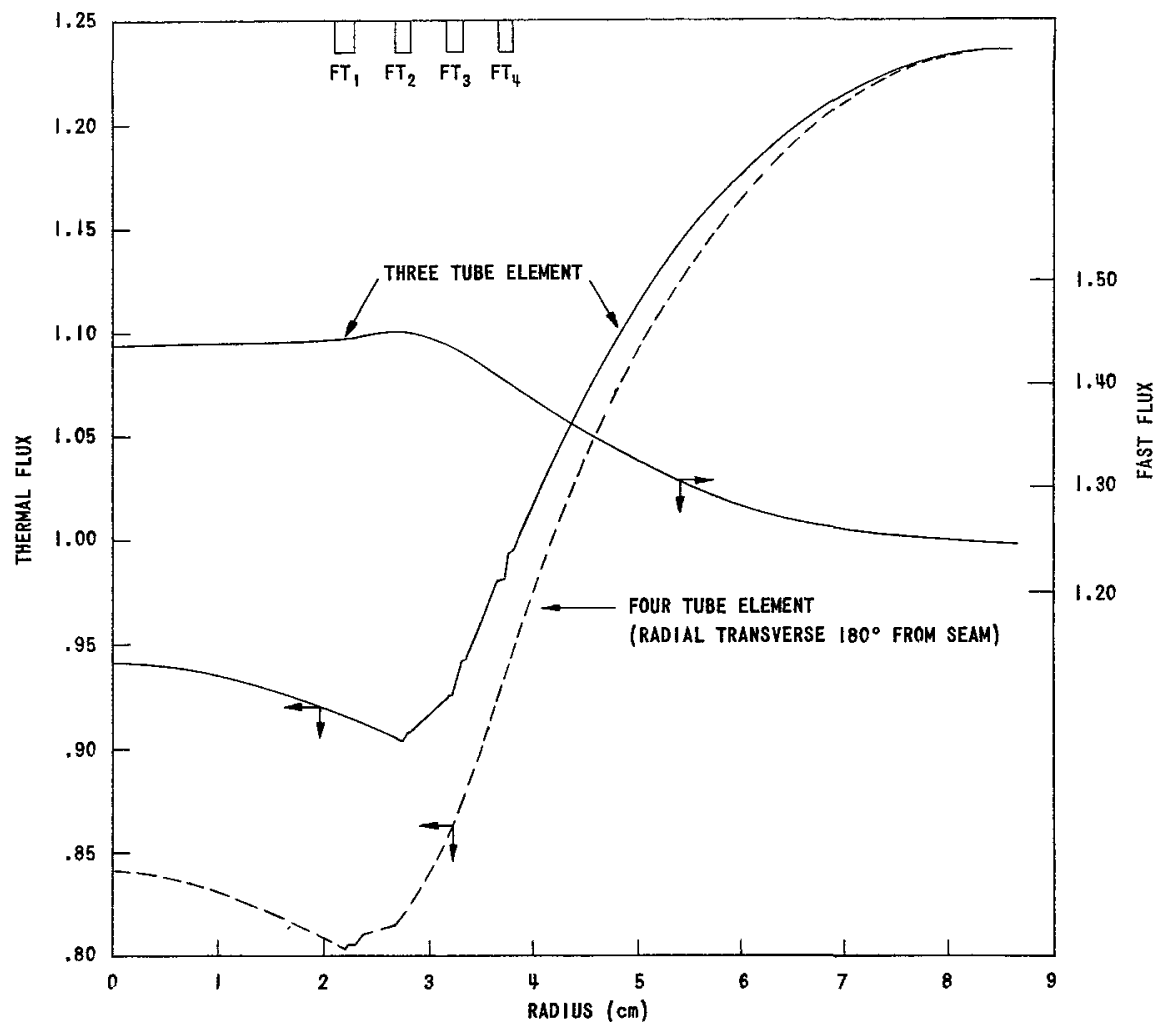

FIG. 6

RADIAL THERMAL AND FAST FLUXES AS CALCULATED BY DIFFUSION THEORY

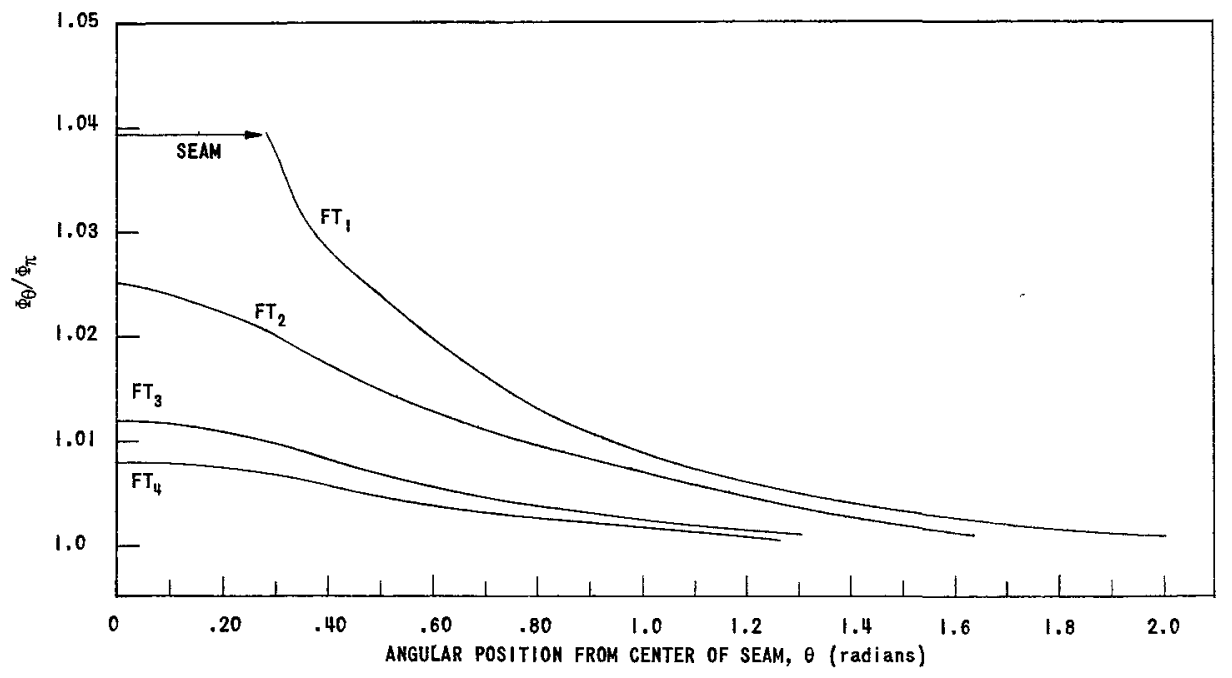

FIG. 7

RATIO OF LOCAL THERMAL FLUX WITHIN MEAT TO THERMAL FLUX OPPOSITE SEAM AS A FUNCTION OF ANGULAR POSITION FROM CENTER OF FUEL THIMELE SEAM (1.27 cm WIDE) 


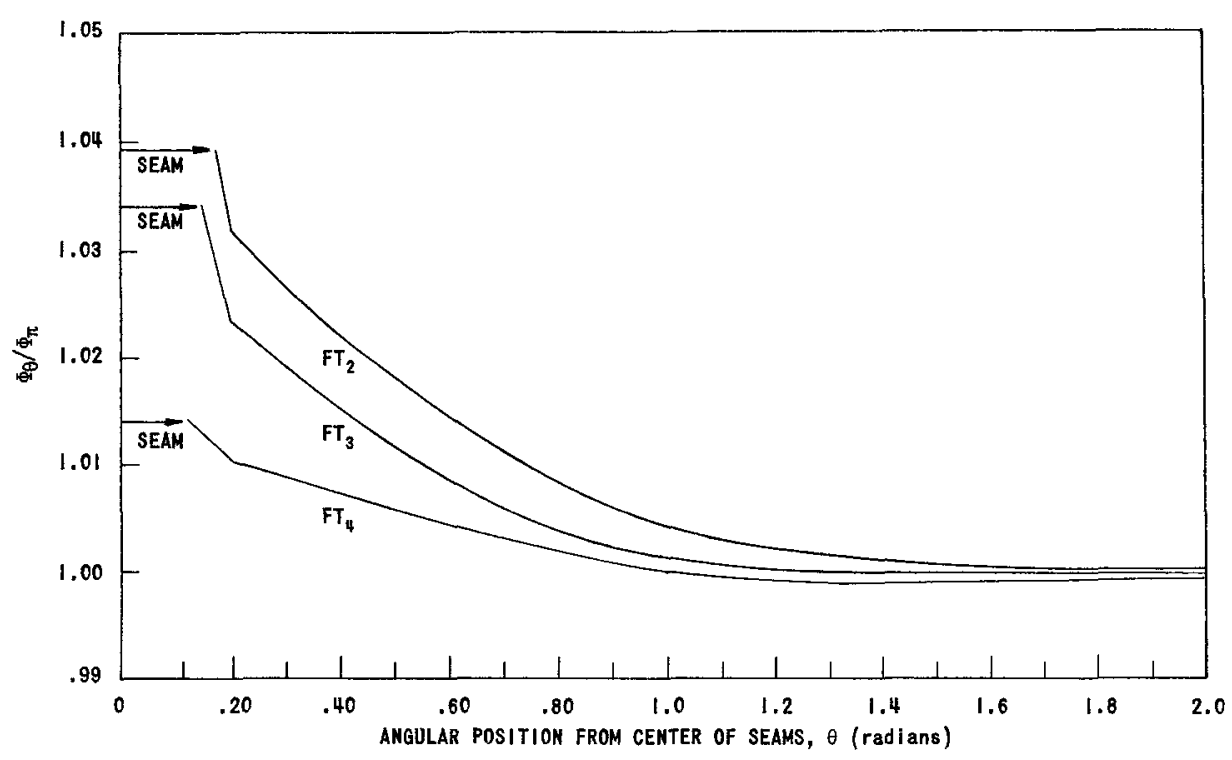

FIG. 8

RATIO OF LOCAL THERMAL FLUX WITHIN MEAT TO THERMAL FLUX OPPOSITE SEAMS AS A FUNCTION OF ANGULAR POSITION FOR FUEL ELEMENT CONTAINING TUBES WITH SEAMS $(0.95 \mathrm{~cm}$ WIDE) IN LINE

The magnitude of the maximum flux peak is decreased as the seam widths are reduced. For example, the maximum peaking factor shown in Fig. 7 for the $1.27-\mathrm{cm}$-wide seam is 1.040 ; if the seam width is reduced to $0.95 \mathrm{~cm}$, the peaking factor is reduced to 1.034 ; if the width is reduced to $0.64 \mathrm{~cm}$, the peaking factor is reduced to 1.024 .

Comparison of the experimental data with the results of the theoretical analysis (see Fig. 7) for a seamed (1.27-cm-wide) fuel thimble located within a standard fuel element indicates that the diffusion calculation underestimates the peaking effect. If the magnitude of the flux peak at the seam is made to agree with experiment by use of the transformation,

$$
\left(\phi_{\theta} / \phi_{\pi}\right)_{\text {adjusted }}=\mathrm{C}\left(\frac{\phi_{\theta}}{\phi_{\pi}}-1\right)+1,
$$

then the width of the peak is overestimated.

A superposition of the adjusted local flux, for various values of $\mathrm{C}$, upon a sinusoidal flux variation resulting from a flux gradient across the fuel thimble is shown in Figs. 9 and 10. These theoretical curves should be compared with the experimental data in Figs. 4 and 5, respectively. 


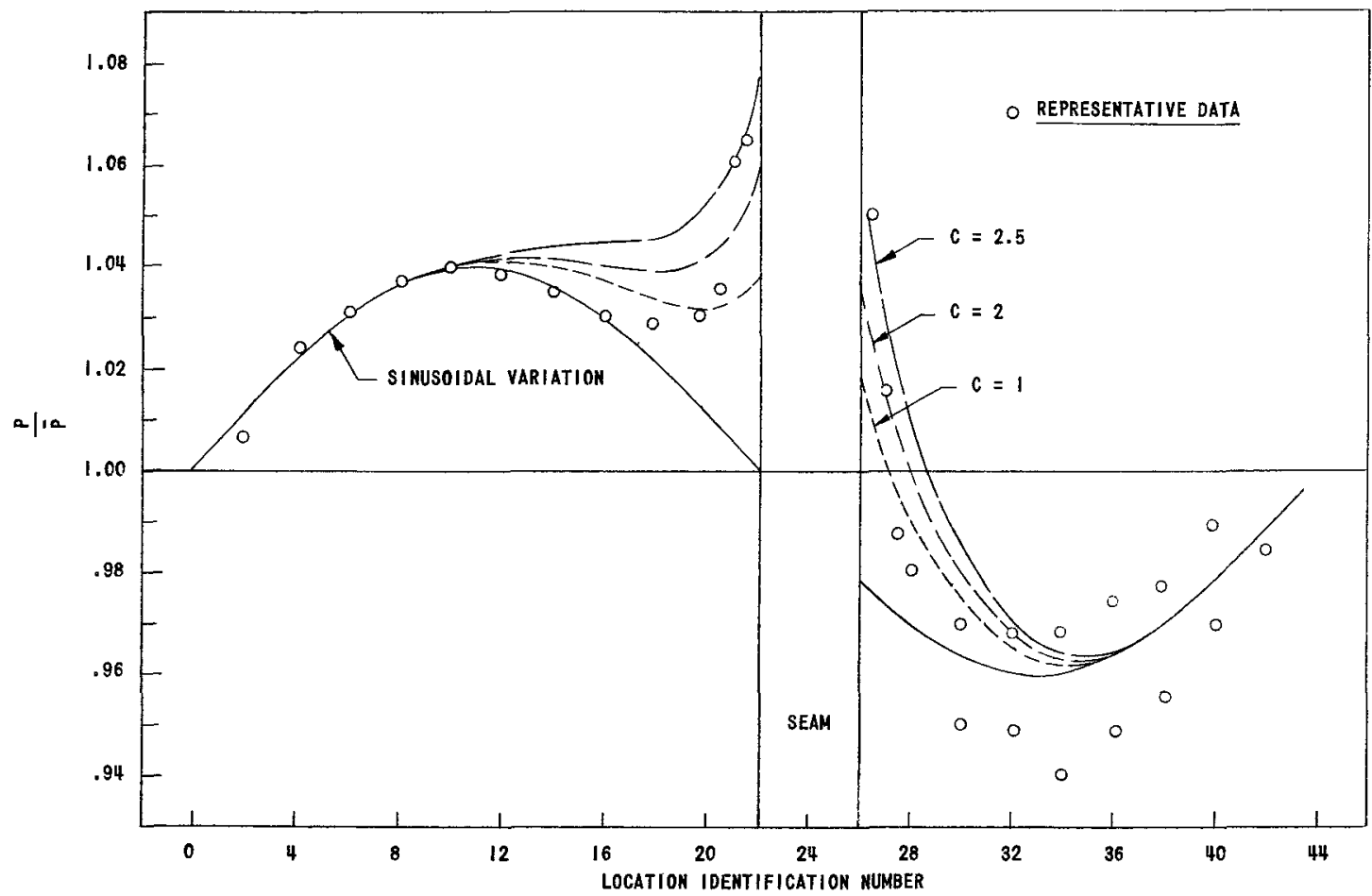

FIG. 9

THEORETICAL RATIO OF LOCAL POWER DENSITY TO AVERAGE POWER DENSITY AS A FUNCTION OF ANGULAR POSITION NEAR THE LOWER END OF THE FUEL THIMBLE

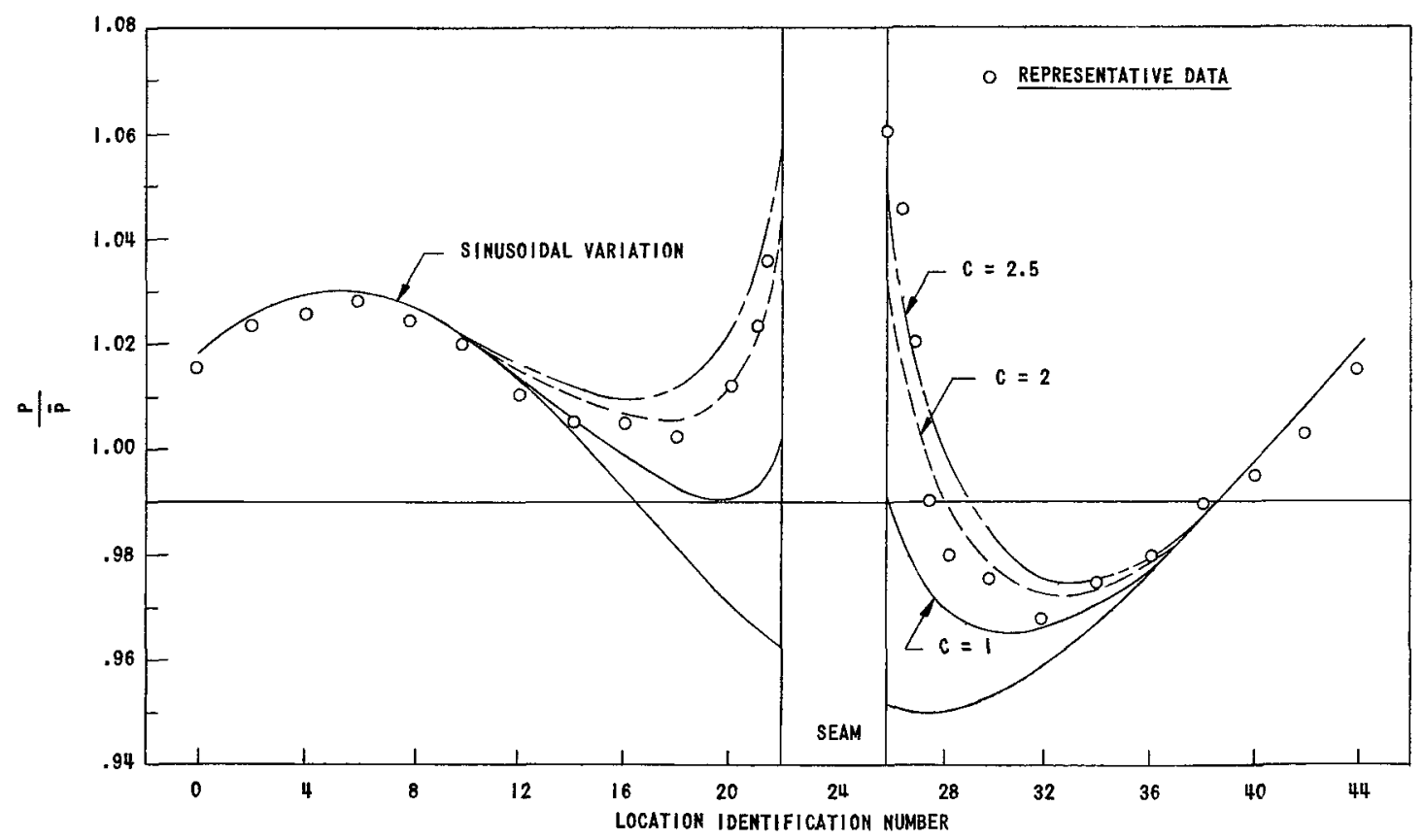

FIG. 10

THEORETICAL RATIO OF LOCAL POWER DENSITY TO AVERAGE POWER DENSITY AS A FUNCTION OF ANGULAR POSITION NEAR THE VERTICAL CENTER OF THE FUEL THIMBLE 
Only fair agreement is obtained. Nonuniformity of the fuel immediately adjacent to the seam gives $\mathrm{rise}$ to an uncertainty in the power density at this location; however, this uncertainty is not significant from the standpoint of determining the maximum surface temperature (see Section V). The discrepancies in the magnitude and shape of the flux near the seam arise from the inadequacy of the diffusion approximation.

In order to predict the peaking effect in the seamed fuel tubes, the theoretical values of $\phi_{\theta} / \phi_{\pi}$ were adjusted using $C=2.5$. This should provide a slight overestimate of the peak fluxes within the fuel tubes. The adjusted theoretical peaking factors for various seam widths and configurations are listed in Table III.

Table III

\section{ADJUSTED THEORETICAL PEAKING FACTORS}

\begin{tabular}{|c|c|c|c|c|c|}
\hline \multirow[b]{2}{*}{ Configuration } & \multirow[b]{2}{*}{ Seam Width, cm } & \multicolumn{4}{|c|}{ Location and Magnitude of Power Peaks ${ }^{a}$} \\
\hline & & Thimble & $\begin{array}{l}\text { Inner } \\
\text { Tube }\end{array}$ & $\begin{array}{l}\text { Intermediate } \\
\text { Tube }\end{array}$ & $\begin{array}{l}\text { Outer } \\
\text { Tube }\end{array}$ \\
\hline $\begin{array}{l}\text { Seamed Fuel Thimble } \\
\text { and Extruded Fuel Tubes }\end{array}$ & 1.27 & 1.100 & 1.063 & 1.030 & 1.020 \\
\hline \multirow[t]{2}{*}{ Three Seams in Line } & 0.79 & - & 1.092 & 1.077 & 1.033 \\
\hline & 0.95 & - & 1.098 & 1.085 & 1.035 \\
\hline Seams $120^{\circ}$ Apart ${ }^{b}$ & 0.95 & - & 1.045 & 1.105 & 1.050 \\
\hline
\end{tabular}

aThese peaking factors are referenced to the power in the meat at an angular position $180^{\circ}$ from the seam and not to the average power density in the fuel.

${ }^{b}$ There is some uncertainty in the peaking factors for this configuration resulting from poor convergence of the problem.

For the configuration with the three seams lined up at the same angular position, the peaks are all located at the edges of the seams. When the seams are $120^{\circ}$ apart, the primary peaks in the intermediate and outer tubes are at the edges of their respective seams. However, the primary peak in the inner tube is at the same angular position as the seam of the intermediate tube. In addition to these peaks, peaks of secondary magnitude are located $120^{\circ}$ apart from the primary ones.

When the seamed fuel thimble is employed, the primary peaks are at the seam-meatinterfaces within the thimble. Secondary peaks are located in the three extruded fuel tubes at the same angular position as the thimble seam. 


\section{TEMPERATURE PEAKING}

The use of longitudinally seamed fuel tubes instead of the extruded type now being employed in CP -5 would have a twofold effect upon the local power generation within the meat section of the tube.

1) If the total $\mathrm{U}^{235}$ content of each seamed tube is kept the same as the $\mathrm{U}^{235}$ content of the equivalent extruded tube, the power density within the meat will of necessity increase a constant amount over that of the extruded tube for the same total reactor power. This is a consequence of the reduced meat volume within the seamed tubes. The factorial increase in the power density within each fuel tube, which is dependent only upon the width of the seam and the diameter of the fuel tube, is given below for two different seam widths.

\begin{tabular}{|c|c|c|c|}
\hline $\begin{array}{c}\text { Seam } \\
\text { Width, cm }\end{array}$ & $\begin{array}{l}\text { Inner } \\
\text { Tube }\end{array}$ & $\begin{array}{c}\text { Intermediate } \\
\text { Tube }\end{array}$ & $\begin{array}{l}\text { Outer } \\
\text { Tube }\end{array}$ \\
\hline 0.79 & 1.048 & 1.040 & 1.035 \\
\hline 0.95 & 1.058 & 1.049 & 1.042 \\
\hline
\end{tabular}

2) Thermal neutron flux peaking at the aluminum seam produces a local power peak at the seam-meat interface. This effect becomes small away from the interface.

The intermediate tube produces the largest fraction (0.434) of the power per fuel tube bundle as well as having the largest (power):(coolant area) ratio. Hence the flux and temperature peaking within this tube will have the most significance.

A heat transfer calculation has been made for the intermediate tube. The following conservative assumptions and procedures were used:

1) The total reactor power is $4 \mathrm{Mw}$, and 15 of the 17 tube bundles are in the reactor.

2) When using the extruded tubes, the difference between the highest clad temperature and its associated coolant temperature is $51^{\circ} \mathrm{C}$.

3) The thermal conductivity of the clad and meat is constant and equal to $149 \mathrm{~kg}-\mathrm{cal} /(\mathrm{hr})\left(\mathrm{m}^{2}\right)\left({ }^{\circ} \mathrm{C} / \mathrm{m}\right)$.

4) The tube can be represented as a flat plate of width equal to the circumference of the tube.

5) The temperature of the plate at any angular position is taken to be its surface temperature (i.e., a one-dimensional model is used). 
6) The seam width is $0.95 \mathrm{~cm}$.

7) The local flux-peaking effect can be represented by a decaying exponential of the form $\phi_{m} e^{-1.04 x}$, where $x$ is the distance in centimeters into the meat from the meat-seam interface.

8) The peaking factor $\phi_{\mathrm{m}}$ at the interface is 1.10 .

This calculation indicated that the temperature peak is located within the meat at a circumferential distance of $1.27 \mathrm{~cm}$ from the seam-meat interface. The magnitude of the temperature peak at this point is the sum of the following three effects:

\section{Effect}

Increase in average power density for a given power due to reduced meat volume.

Effect of referencing local peaking factor to average power density instead of to power density opposite seam.

Local temperature increase due to flux peaking.
Fuel Power Temperature Density Factor Change, ${ }^{\circ} \mathrm{C}$

1.049 $+2.4$

0.990 $-0.5$

$1.10 e^{-1.04 X} \frac{+1.1}{+3.0}$

For a given average power density, the increse in temperature $\left(+0.6^{\circ} \mathrm{C}\right)$ due to the local flux peaking at the seam is relatively small because the seam, acting as a thermal fin, provides a large effective area for heat transfer at the position of maximum power. The increase in temperature due to the increased average power density in the fuel is larger but still insignificant with respect to other peaking effects.

For the 0.79-cm-wide seam, the maximum temperature rise would be slightly less than for the above case, or $+2.6^{\circ} \mathrm{C}$. The best arrangement of the seamed fuel tubes would have all three seams lined up at the same angular position. This insures that the power peaks occur only near the seams where the heat transfer area is large enough to minimize the temperature rise due to the local power increase. 


\section{CONCLUSIONS}

Seamed fuel tubes will not cause appreciable peaking of the fuel surface temperature if used in CP-5. In order to maintain the same maximum clad temperature at a given coolant flow rate if seamed fuel tubes are used, the total reactor power would have to be maintained at $95 \%$ of the maximum power level allowable using extruded tubes.

Comparison of a prediction of the flux peaking at the seams by diffusion theory with certain experimental data leads to the expected conclusion that simple theory tends to underestimate the peaking effect. If the theoretical values are adjusted to give an accurate maximum flux, the resultant total power increase is too large. Use of the adjusted peaking factors results in a conservative estimate of the temperature peaking. A more accurate estimation of the temperature peaking would be obtained by using the unadjusted theoretical flux values $(C=1)$ or flux values adjusted to give the correct peak width as well as correct maximum flux, since the peak temperature occurs away from the seam where the experimental data lies well below the experimental curves (see Figs. 9 and 10). These details are relatively unimportant since the peaking is very small.

\section{ACKNOW LEDGMENTS}

The author would like to thank H. C. Stevens and V. O. Hartig for their efforts in the design of the gamma-scanning experiment. Special equipment for this experiment was designed and fabricated by E. K. Hedlund. Recognition is also due Judith Koerner whose perseverance and good humor were an immeasurable help in the calculations using the CURE code. 